\title{
A cohort study of the effect of winter dysentery on herd-level milk production
}

\author{
Ingrid Toftaker, ${ }^{* 1}$ Ingrid Holmøy, ${ }^{*}$ Ane Nødtvedt, ${ }^{*}$ Olav Østerås, $†$ and Maria Stokstad* \\ ${ }^{*}$ Department of Production Animal Clinical Sciences, Norwegian University of Life Sciences, PO Box 8146 Dep, 0033 Oslo, Norway \\ †TINE SA, PO Box 58, 1431 Ås, Norway
}

\section{ABSTRACT}

Winter dysentery (WD) is a contagious disease caused by bovine coronavirus. It is characterized by acute onset of diarrhea, fever, depression, and reduced milk yield in adult cattle. Although production loss is a well-known consequence of WD, large-scale studies estimating the effect on milk production are lacking. The objective of this study was to estimate the effect of farmer-reported WD on herd-level milk production and milk composition. A cohort study was performed based on reports of herd outbreaks of winter dysentery during a regional epidemic in Norway during the winter of 2011-2012. Reports were made by farmers, and diagnosis was based on a herd outbreak of acute diarrhea in adults. Milk shipment data were retrieved from the dairy company, and information on herd size and milking system were retrieved from the Norwegian Dairy Herd Recording System. We compared milk production in herds with reported outbreaks of WD $(\mathrm{n}=224)$ with all herds in the same area without a reported outbreak $(\mathrm{n}=2,093)$ during the same period. The outcome variable in the analysis was milk volume per cow per day, and the main predictor was whether the herd had a reported outbreak of WD or not. We assessed the effect of WD on milk production by fitting a linear mixed model, adjusting for milk production in the herd before the outbreak. Similarly, we assessed the effect of WD on milk composition using linear regression, adjusting for the levels of milk components before the outbreak. This study estimated a total loss of $51 \mathrm{~L} /$ cow during the study period, from $7 \mathrm{~d}$ before to $19 \mathrm{~d}$ after a reported outbreak. The lowest estimated production was $2 \mathrm{~d}$ after the outbreak was reported, when the average milk yield was $19.4 \mathrm{~L} /$ cow per day, compared with $23.0 \mathrm{~L} /$ cow per day 7 days before notification (i.e., a difference of $3.6 \mathrm{~L} /$ cow, or $15 \%$ ). The effect gradually declined with time. The estimated effect on milk composition was modest, but an increase of $11 \%$ in free fatty acids

\footnotetext{
Received January 17, 2017.

Accepted April 18, 2017.

${ }^{1}$ Corresponding author: ingrid.toftaker@nmbu.no
}

and a small increase in fat/protein ratio indicated that WD might put cows into negative energy balance. Descriptive analysis indicated that herd milk yield was still reduced 4 mo after an outbreak. This cohort study showed that WD causes considerable decreases in milk production, and it alters milk composition. These findings highlight the important negative consequences of WD, and should motivate actions to prevent betweenherd spread of bovine coronavirus.

Key words: dairy, bovine coronavirus, milk composition, milk yield

\section{INTRODUCTION}

Winter dysentery (WD) in dairy herds is characterized by the sudden onset of diarrhea in several adult cattle (Clark, 1993). It typically occurs as epidemics during the winter, and is caused by bovine coronavirus, which is endemic in cattle populations worldwide (Saif, 1990; Alenius et al., 1991; Paton et al., 1998; Boileau and Kapil, 2010). Previous studies have shown high prevalence in the Norwegian national dairy herd as well. Gulliksen et al. (2009) found that 39\% of examined calves were antibody positive, and Toftaker et al. (2016) found antibodies in bulk tank milk in $72 \%$ of all study herds. Bovine coronavirus also causes calf diarrhea and respiratory disease in both calves and adult animals (Boileau and Kapil, 2010). The clinical signs of WD include watery diarrhea with or without blood in the feces, fever, depression, decreased milk production, anorexia, and sometimes cough or nasal discharge (Boileau and Kapil, 2010). Mortality is low, but morbidity in affected herds is high, and outbreaks can result in poor herd health and reduced animal performance (Clark, 1993; Tråvén et al., 2001; Boileau and Kapil, 2010). Reduced milk production is an important consequence for the farmer, because of associated economic losses. The acute drop in milk yield associated with WD is well known, but estimates of the magnitude of this drop are often based on a few animals or on outbreaks in only a few herds. Furthermore, the reported magnitude of this drop varies widely (Durham et al., 1989; Fleetwood et al., 1989; Tråvén et al., 2001). 
Diseases associated with reduced general condition often result in reduced milk production. A rapid decrease in milk yield has been described for several viral diseases in cattle, including foot and mouth disease, bovine herpesvirus 1 infection, and bovine leukemia virus infection (Lyons et al., 2015; Statham et al., 2015; Yang et al., 2016). Studies have also shown that viral infections can affect milk quality (Rola et al., 2015; Yang et al., 2016). However, this has not previously been shown for WD on a larger scale. Possible effects on milk composition are important because altered composition could adversely affect milk quality, which in turn has economic consequences for the farmer and the processing industry.

The Norwegian dairy herd is a suitable study population for quantifying the effects of $\mathrm{WD}$, because the presence of other endemic diseases that could confound results is low. This also means that the list for differential diagnosis of WD is limited. Norwegian cattle are free of many infectious agents such as bovine viral diarrhea virus, bovine herpes virus 1, Mycobacterium avium ssp. paratuberculosis, and Brucella abortus, and they are virtually free of Salmonella spp. (prevalence $<0.5 \%$ in farmed species; Sviland et al., 2015; Åkerstedt et al., 2016a; Åkerstedt et al., 2016b; Heier et al., 2016).

The endemic occurrence of bovine coronavirus regularly causes respiratory disease and diarrhea, and is a concern for animal health and economic sustainability (Gulliksen et al., 2009; Klem et al., 2014). Large-scale observational studies estimating the effect of WD on milk production under field conditions are lacking, and further knowledge in this area is in demand. Reliable estimates of both the magnitude and duration of effect of WD on milk production are important for motivating famers and others to prevent the spread of bovine coronavirus between herds. Furthermore, quantifying the effects of WD on milk composition would add valuable input to the overall picture of the economic consequences of this disease. The objectives of this study were to estimate the effect of an outbreak of farmer-reported WD on (1) herd-level milk production, as measured by volume of milk per cow per day at the time of outbreak, and (2) herd-level milk composition. A secondary objective was to explore the duration of the effect on milk production.

\section{MATERIALS AND METHODS}

\section{Background}

During the winter of 2011-2012, a seasonal epidemic of WD took place in Norway. It started in the eastern part of the country in the autumn, and spread in an epidemic pattern throughout most parts of the coun- try. Initially, bovine coronavirus was confirmed as the causative agent in a limited number of herds by antigen (PCR) or antibody detection (seroconversion), or both. Salmonellosis, bovine viral diarrhea, and Schmallenberg virus infection were ruled out. Later in the outbreak, laboratory confirmation of the diagnosis was usually not performed. During this epidemic, the advisory service of the largest dairy company (TINE SA) developed a voluntary surveillance system in the eastern part of Norway, where farmers and veterinarians were encouraged to report outbreaks of contagious diarrhea, so that herd-level biosecurity measures could be implemented. The farmers were advised to report outbreaks of acute diarrhea affecting several adult cattle. These reports were the basis for the present study.

\section{Study Population}

In total, 241 cases of farmer-reported WD in dairy herds were made from November 4, 2011, to March 13, 2012. These reports were from 7 counties in eastern Norway: Østfold, Akershus, Oslo, Hedmark, Oppland, Buskerud, and Vestfold, which constituted the study area and defined the source population. We performed a cohort study, the study unit being the herd. Herds from which outbreaks were reported by the producer were considered exposed (WD+). All other dairy herds in the same area were considered non-exposed (WD-). Inclusion criteria were member of the Norwegian Dairy Herd Recording System; milk shipment data available for the time of the outbreak (at least $21 \mathrm{~d}$ before and 19 $\mathrm{d}$ after the day of notification); and location within the study area. In this study, the day the farmer notified the advisory service of a current outbreak was day 0 , and all references to time were relative to this. Because all included herds had milk shipments throughout the study period, study groups were considered closed, and a risk-based design was applied (Dohoo et al., 2009). For a visual overview of all study herds with respect to exposure status, a point map was made.

\section{Data}

Access to milk shipment data on volume and composition was provided by the dairy company (TINE SA). The total volume of milk was recorded for each shipment (i.e., every time the milk truck collected milk from the farm bulk milk tank). Milk quality was evaluated at the dairy plant by analyses of milk composition approximately twice per month. The number of cows contributing monthly test day samples was retrieved from the Norwegian Dairy Herd Recording System, along with data on the average annual herd size, milking system, and production type (freestall/tiestall). 


\section{Variables}

Outcome Variables. The continuous outcome variable was herd-level milk production, measured by volume of milk per cow per day. This was calculated as follows. The volume of milk shipped on each shipment date was divided by the number of days since the last shipment to obtain the herd's daily milk production. The number of cows contributing to the bulk tank each day was estimated from the number of cows contributing on 2 consecutive monthly test days, calculating the average change in herd size per day, allowing imputation of the average herd size per day for all days between test days. The volume of milk per day was then divided by the estimated number of cows on that day to obtain herd-level milk production. Available data on milk composition consisted of records for fat, urea, protein, lactose, free fatty acids, and SCC in the analysis description. Fat, protein, urea, and lactose were measured in \%, free fatty acids was measured in millimoles per liter and SCC was measured in 1,000 cells/mL of milk.

Explanatory Variables. The main predictor (i.e., exposure of interest), was the binary variable of whether or not a herd had a reported an outbreak of $\mathrm{WD}(\mathrm{WD}+/-)$. To obtain comparable time at risk for the exposed and non-exposed herds, we simulated a set of pseudo-notification dates for the non-exposed herds using frequency distribution of the actual notification dates. A pseudo-notification date was randomly assigned to each of the non-exposed herds using a list of computer-generated random numbers. In this way, milk production for the period around the outbreak for WD+ herds and around the pseudo-outbreak for WD- herds could be compared.

To account for any initial differences in milk production between WD+ and WD- herds, we calculated pre-outbreak milk production as average production (L/cow per day) for the time period from 21 to $8 \mathrm{~d}$ before the day of notification for each herd. We estimated the number of cows contributing to the bulk tank each day as described for herd-level milk production. Records from the last week before the notification date were omitted to avoid overlap with the disease period, because the accuracy of the reported time of outbreak was unknown. In a similar way, we calculated the average values of the different milk components for the period from 21 to $8 \mathrm{~d}$ before the outbreak. The time variable was the time relative to the notification date. The average annual herd size was retrieved from the annual summary tables of the Norwegian Dairy Herd Recording System, using the number of cow-years in 2012 (or 2011 for the herds that lacked a record for
2012). One "cow-year" equaled 365 cow days at risk. Milking system was divided into 3 categories: automatic milking system, pipeline milking, and milking parlor. Information on whether the herd had tiestalls or freestalls was also included.

\section{Descriptive Statistics}

We assessed the distribution of milk production and herd size among WD+ and WD- herds using histograms (results not shown). We calculated mean values and spread for herd characteristics and main variables with respect to the herd's exposure status (WD+/-), along with descriptive statistics for milk composition before and after the outbreak/pseudo-outbreak in $\mathrm{WD}+$ and WD- herds, respectively. We explored the duration of effect beyond the modeled time period by calculating the average production in $20 \mathrm{~d}$ intervals (i.e., the first interval was d 10-29, the next d 30-49, and so on). We did this for all herds with available records, up to d 150. To assess the spread of the drop in milk production, we calculated the maximum difference between pre-outbreak milk production and herd-level milk production for each herd, and visualized it in a histogram.

\section{Multivariable Models}

Milk Production. We identified possible confounders for the effect of WD on herd-level milk production through a causal diagram, and evaluated their effects by closely monitoring the other estimates as a potential confounder was included and removed from the multivariable model. Variables assessed as possible confounders were herd size, milking system, and milk production in the period before the outbreak. The distribution of DIM was also calculated in both groups of herds. Pairwise correlations between all predictors were assessed. To allow for a different effect of time since outbreak/pseudo-outbreak for WD+ and WDherds, an interaction term between WD and number of days since outbreak was included in the model. To assess linearity for the continuous predictor days after outbreak, smoothed line plots were drawn visualizing their relationship with the outcome. For the WD+ herds, the relationship was clearly nonlinear, so different transformations were tried. Models were compared based on Akaike's information criteria, and the best fit was accomplished by modeling the interaction term as a cubic spline. Knots were chosen a priori based on biological considerations, and knots at d $-3,2,7$, and 14 were used (Vittinghoff et al., 2012). Finally, assessment of the effect of WD on milk production was 
carried out by fitting a linear mixed model with a herd random effect to account for dependence between repeated milk shipments from each herd. The model was fit using a manual backward stepwise procedure, with a selection threshold of $P<0.05$. We used the restricted maximum likelihood approach. Ten different correlation structures were explored for the random effect: autoregressive (AR1 and AR2), moving average (MA1) and Toeplitz 1 to 7 . The different correlation structures were evaluated by comparing log-likelihood and Akaike's information criteria. Residuals on herd and shipment level were assessed for possible outliers and normality plots, and plots of residuals against predicted values were made. Predicted values were calculated, and average herds in terms of milk production before outbreak were visualized through a line plot. To obtain confidence intervals for selected predicted values, the variance was calculated as suggested by Kleinbaum et al. (1982). The total loss per cow over the study period was calculated as the difference in estimated milk production per day between WD+ and WD- herds plus the initial difference at the start of the study period $(\mathrm{d}$ $-7)$.

Milk Composition. We assessed the effect of WD on 6 different milk components: fat, urea, protein, fat/ protein ratio, lactose, free fatty acids, and SCC. Free fatty acids and SCC were log-transformed. Records for milk composition were available for a subset of the study population, consisting of 1,539 farms: 167 WD + and 1,372 WD-. We used the first available milk composition analysis before d 20 for this part of the analysis. Assessment of the effect of WD on the different outcomes of milk composition were performed by linear regression, adjusting for the level of the outcome measure before the outbreak, as described in the milk production section. Possible confounding factors were identified using a causal diagram and monitored by calculating the changes in other covariates when one factor was added and withdrawn from the model. For all outcomes, final models were fitted using a manual backward stepwise procedure with a selection threshold of $P<0.05$.

\section{Software}

Data set assembly was done in SAS (version 9.3; SAS Institute Inc., Cary, NC) and further processing and data analyses were performed using Stata (Stata SE/14; Stata Corp., College Station, TX). Maps of the study area and study population were created in QGIS 2.12.2 (QGIS Development Team, QGIS Geographic Information System, Open Source Geospatial Foundation, http://qgis.osgeo.org).

\section{RESULTS}

\section{Descriptive Statistics}

The final study population consisted of 2,317 herds: $224 \mathrm{WD}+$ and 2,093 WD-. For an overview of eligible and analyzed herds, see Figure 1. An overview of the location of all study herds, together with their exposure status, is presented in Figure 2. Descriptive statistics of daily milk production 21 to $8 \mathrm{~d}$ before notification, daily milk production 0 to $19 \mathrm{~d}$ after notification, herd size, milking system, and production type (freestall/ tiestall) in WD+ and WD- herds are shown in Table 1. The study herds had milk shipments 1 to 16 times, with a mean of 11 shipments from $7 \mathrm{~d}$ before to 19 d after the day of notification. Milk shipments happened at uneven intervals, typically with either 2 or 3 $\mathrm{d}$ intervals [mean 2.5, SD 1.4]. The distribution of milk components in the WD+ and WD- groups is shown in Table 2. The average herd size was 25.7 cow-years (SD 16.0), and the overall average milk production from 21 to $8 \mathrm{~d}$ before the outbreak was $22.2 \mathrm{~L} / \mathrm{cow} /$ day (SD 6.0). Smoothed line plots of milk production in WD+ and WD- herds are shown in Figure 3. The spread in maximum herd-level milk drop (herd-level milk production - pre-outbreak milk production) was illustrated by the interquartile range: 13 to $29 \%$. The distribution is visualized in Figure 4. For $2 \mathrm{WD}+$ herds we found no drop in milk production. For 212 of the $224 \mathrm{WD}+$ herds and 1,977 of the 2,317 WD- herds, we were able to follow milk production up to $150 \mathrm{~d}$ after the outbreak. The average milk production between 130 and $150 \mathrm{~d}$ after reporting was $22.4 \mathrm{~L} /$ cow per day (SD 5.9) for $\mathrm{WD}+$ herds and $22.7 \mathrm{~L} /$ cow per day (SD 5.8) for WD- herds. For these herds, milk production before the outbreak was $23.8 \mathrm{~L} /$ cow per day (SD 4.9) for WD+ herds and $22.1 \mathrm{~L} /$ cow per day (SD 6.0) for WD- herds, suggesting that more than 4 mo later, the WD+ herds still had not regained the production they had before the outbreak. The WD- herds had a slight increase in milk production during the same period.

\section{Statistical Analysis}

Milk Production. We detected no indications of multicollinearity for the factors in the model. Of the variables considered as possible confounders, only preoutbreak milk production was kept in the final model: introducing pre-outbreak milk production led to a large change in the estimated effect of the primary predictor $\mathrm{WD}+/-$. Including milking system produced only negligible changes in the estimate of the main predictor $(3 \%)$, and because this variable had a considerable number of missing observations ( $13 \%$ of herds), it was 


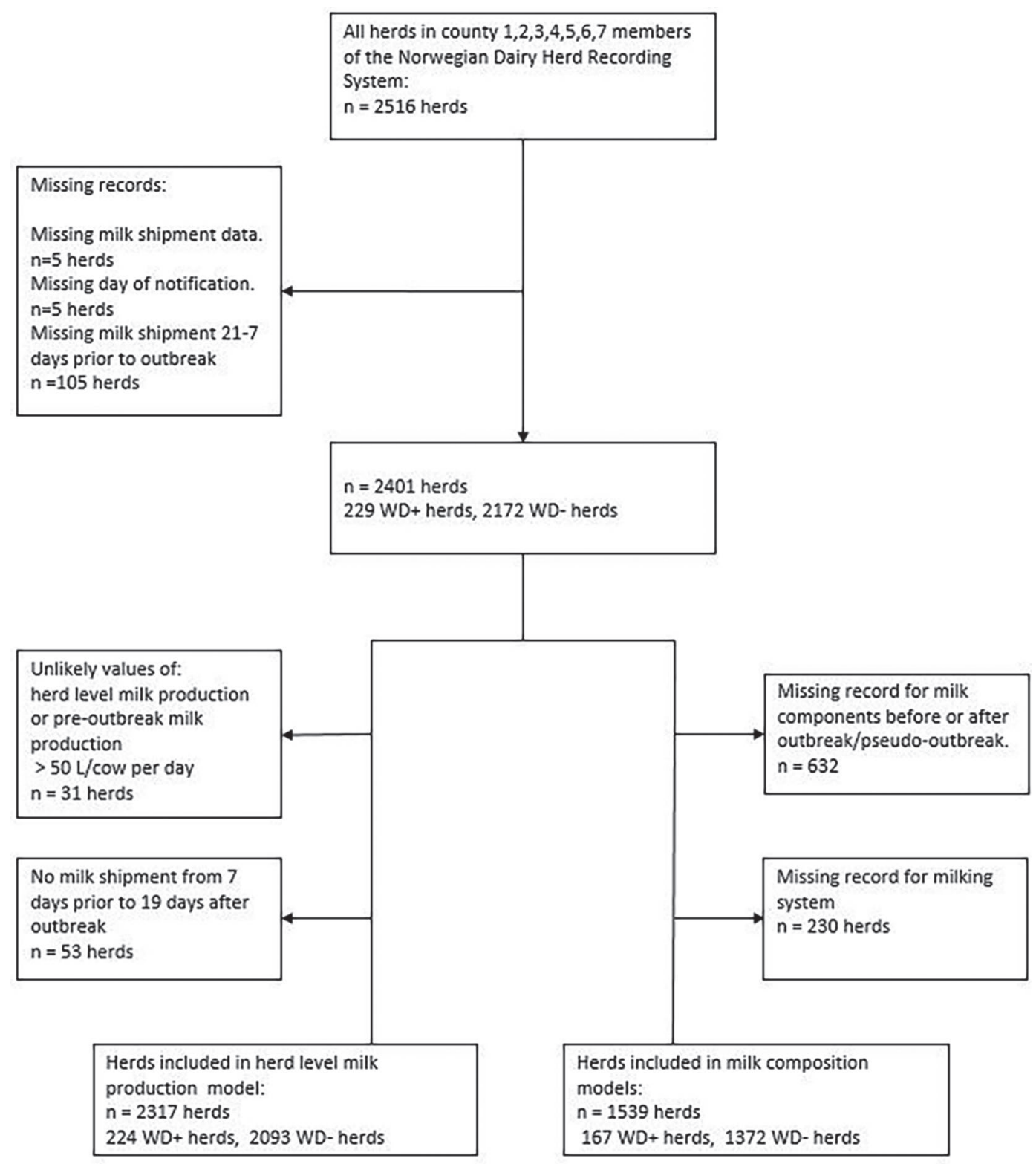

Figure 1. Flowchart of eligible and analyzed herds. Herds that reported an outbreak of winter dysentery were WD + herds, and herds that did not make a report were WD- herds.

not included in the final model. Herd size was not significant $(P>0.05)$ in the model, and its effect on the coefficient of the main predictor was negligible, so it was also omitted. The distribution of DIM was virtually identical in the 2 groups and was not included in the model. The best model fit was achieved by applying a Toeplitz 6 correlation structure. Residual plots revealed no major shortcomings.

Estimates from the linear mixed model are presented in Table 3, and predicted milk production values for the average herd (milk production before outbreak) in the period around outbreak are shown in Figure 5.
The predicted maximum difference in milk production between $\mathrm{WD}+$ and $\mathrm{WD}-$ herds occurred at $\mathrm{d} 2$. Furthermore, the model predicted that a herd with average milk production before an outbreak would fall from $23.0 \mathrm{~L} /$ cow per day $(95 \%$ CI: $22.6-23.4 \mathrm{~L} /$ cow per day) $7 \mathrm{~d}$ before an outbreak to $19.4 \mathrm{~L} /$ cow per day (95\% CI: 19.1-19.8) 2 d after an outbreak, whereas for a WD - herd we estimated a slight increase $(<0.1 \mathrm{~L})$ in milk yield during the same period. This equaled an estimated maximum herd-level drop in milk yield of $15 \%$ for a WD+ herd. The effect gradually declined over time and, around d 10 the slope for milk produc- 


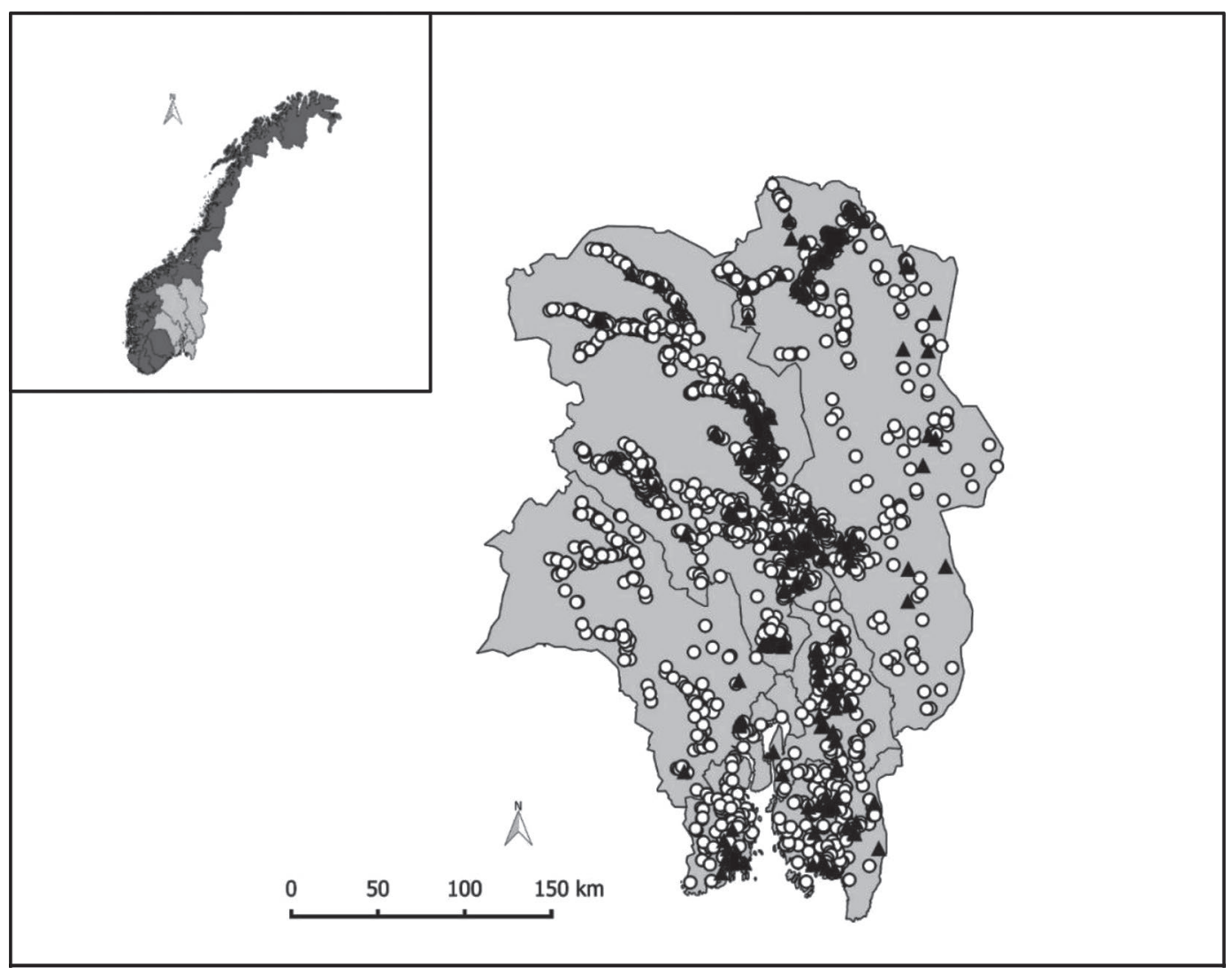

Figure 2. The study area consisting of 7 counties in eastern Norway. The black triangles $(\mathrm{n}=224)$ were herds that reported an outbreak of winter dysentery, and the white dots $(\mathrm{n}=2,093)$ were herds that did not make a report during the study period (November 4,2011 , to March $13,2012)$.

tion flattened out for the WD+ herds. However, they did not completely regain the milk production they had before the outbreak within the modeled time period (Figure 5). For an average herd, the total estimated loss was $51 \mathrm{~L} /$ cow over the study period, from $7 \mathrm{~d}$ before to $19 \mathrm{~d}$ after the day of notification.

Milk Composition. Records on milk composition from d 0 to 19 were available for 1,539 herds: $167 \mathrm{WD}+$

Table 1. Descriptive statistics for the main variables and herd characteristics among herds that reported an outbreak of winter dysentery $(\mathrm{WD}+)$, and herds that did not report an outbreak (WD-)

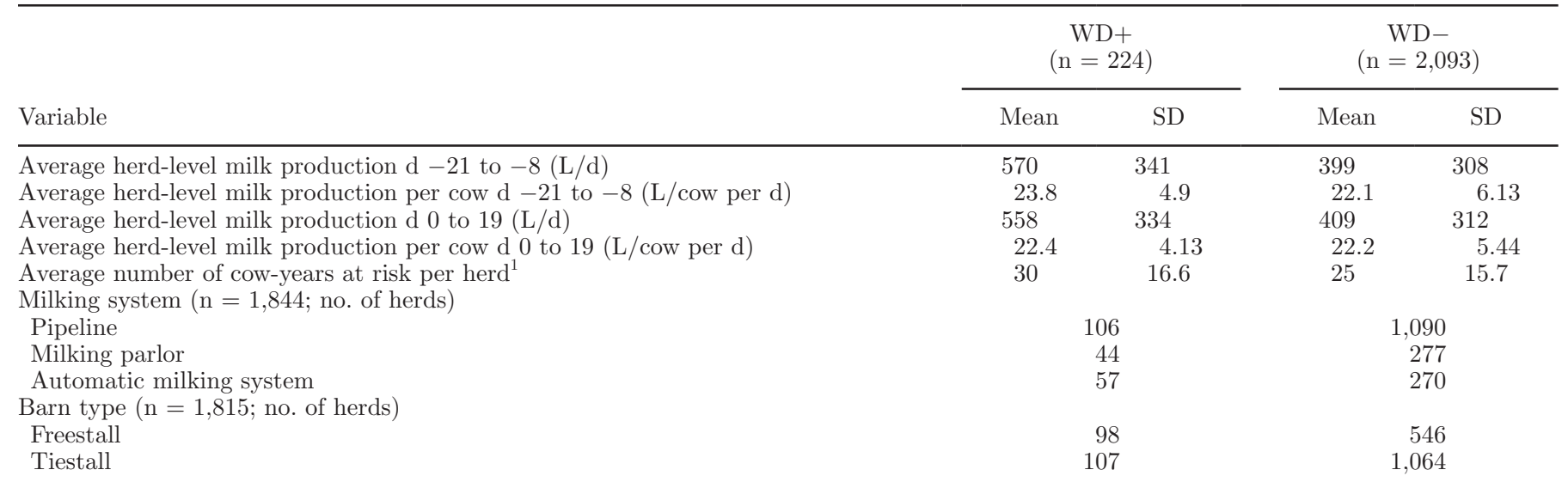

${ }^{1}$ Number of cow-years at risk in 2012 or 2011 for all herds that had missing record for 2012, in total this includes $\mathrm{n}=2,069,223 \mathrm{WD}+$ and $1,846 \mathrm{WD}$ - herds. 

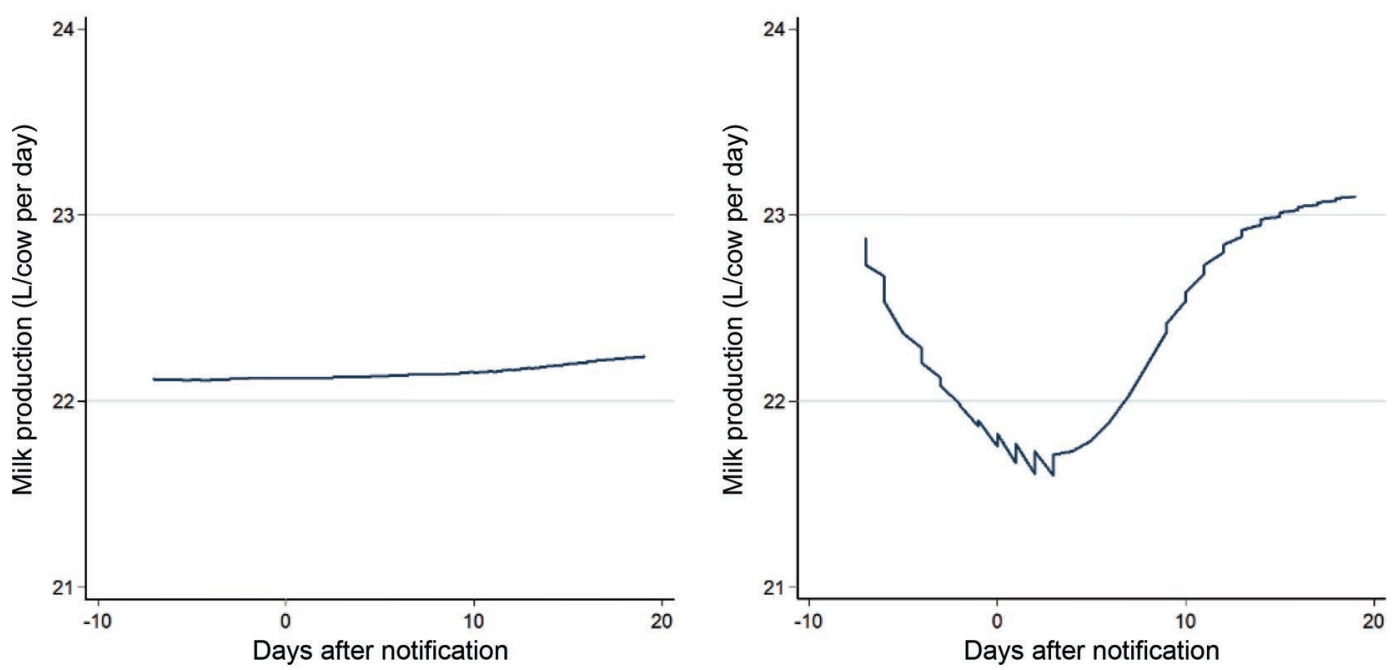

Figure 3. Smoothed line plots of the relationship between the number of days after notification and herd-level milk production (in L/cow per day) in herds that did not report winter dysentery (WD-; left) and herds that reported an outbreak of winter dysentery (WD+; right). Color version available online.

and 1,372 WD-. The median time of first available composition analysis after outbreak was at d 8. Herd size and milking system were tested in the models as possible confounders, and after a backward stepwise elimination procedure, milking system was kept in the model for lactose, protein, and free fatty acids. Herd size was not significant in any of the models, and was therefore omitted. The effect of WD on milk composition was statistically significant $(P<0.05)$ for fat, protein, fat/protein ratio, lactose, and free fatty acids. We were unable to detect any significant effect on urea or SCC. For fat, protein, and lactose, the estimated effect of WD was small (i.e., $<1 \%$ difference between $\mathrm{WD}+$ and $\mathrm{WD}-$, given equal values before outbreak/ pseudo-outbreak, results not shown). The observed effect of WD on fat/protein ratio was also small, in the direction of increased fat/protein ratio for $\mathrm{WD}+$ herds: the estimated coefficient of WD was 0.018 (95\% CI: $0.009-0.027)$. For free fatty acids, the estimated coefficient of WD was 0.010 (95\% CI: 0.027-0.18), meaning the estimated average content of free fatty acids on the original scale was $0.029 \mathrm{mmol} / \mathrm{L}$ higher for a WD+

Table 2. Descriptive statistics for milk composition before and after outbreak/pseudo-outbreak in herds that reported an outbreak of winter dysentery (WD+), and herds that did not report an outbreak (WD-)

\begin{tabular}{|c|c|c|c|c|}
\hline \multirow[b]{2}{*}{ Milk composition } & \multicolumn{2}{|c|}{$\begin{array}{c}\text { WD+ } \\
(\mathrm{n}=167)\end{array}$} & \multicolumn{2}{|c|}{$\begin{array}{c}\text { WD- } \\
(\mathrm{n}=1,372)\end{array}$} \\
\hline & Mean & SD & Mean & SD \\
\hline \multicolumn{5}{|l|}{ Before outbreak $^{1}$} \\
\hline Fat $(\%)$ & 4.08 & 0.23 & 4.14 & 0.29 \\
\hline Protein (\%) & 3.34 & 0.14 & 3.38 & 0.19 \\
\hline Fat/protein ratio & 1.22 & 0.069 & 1.23 & 0.071 \\
\hline Urea $(\%)$ & 5.54 & 0.96 & 5.59 & 0.99 \\
\hline Lactose (\%) & 4.61 & 0.08 & 4.58 & 0.16 \\
\hline Free fatty acids $(\mathrm{mmol} / \mathrm{L})$ & 0.28 & 0.20 & 0.33 & 0.23 \\
\hline $\mathrm{SCC}\left(\times 10^{3}\right.$ cells $\left./ \mathrm{mL}\right)$ & 138 & 79.2 & 141 & 83.2 \\
\hline \multicolumn{5}{|l|}{ After outbreak $^{2}$} \\
\hline Fat $(\%)$ & 4.16 & 0.28 & 4.12 & 0.30 \\
\hline Protein (\%) & 3.30 & 0.14 & 3.37 & 0.19 \\
\hline Fat/protein ratio & 1.25 & 0.098 & 1.23 & 0.074 \\
\hline Urea $(\%)$ & 5.50 & 1.06 & 5.53 & 0.99 \\
\hline Lactose (\%) & 4.60 & 0.09 & 4.59 & 0.15 \\
\hline Free fatty acids $(\mathrm{mmol} / \mathrm{L})$ & 0.32 & 0.20 & 0.33 & 0.21 \\
\hline $\mathrm{SCC}\left(\times 10^{3}\right.$ cells $\left./ \mathrm{mL}\right)$ & 147 & 83 & 147 & 94 \\
\hline
\end{tabular}

${ }^{1}$ Average level of milk component in the period from 21 to $8 \mathrm{~d}$ before outbreak/pseudo-outbreak.

${ }^{2}$ Average level of milk component in the period from 0 to $19 \mathrm{~d}$ after outbreak/pseudo-outbreak. 
Table 3. Results from a linear mixed model with a herd random effect and a Toeplitz 6 correlation structure estimating the effect of winter dysentery (WD) on herd-level milk production (L/cow per day) in 2,317 herds $(224 \mathrm{WD}+$ and $2,093 \mathrm{WD}-)$

\begin{tabular}{lccccc}
\hline & Coefficient & SE & $P>|z|$ & $95 \%$ Lower & $95 \%$ Upper \\
\hline Intercept & 4.93 & 0.20 & $<0.01$ & 4.53 & 5.32 \\
WD $^{1}$ & -2.52 & 0.21 & $<0.01$ & -2.93 & -2.12 \\
Pre-outbreak milk production $^{2}$ & 0.77 & 0.009 & $<0.01$ & 0.75 & 0.79 \\
Days $^{3}$ & 0.0065 & 0.003 & 0.023 & 0.0007 & 0.012 \\
Slope $^{4}$ & -0.50 & 0.024 & $<0.01$ & -0.55 & -0.45 \\
Slope $2^{4}$ & 2.05 & 0.10 & $<0.01$ & 1.85 & 2.26 \\
Slope $3^{4}$ & -5.01 & 0.30 & $<0.01$ & -5.56 & -4.46 \\
\hline
\end{tabular}

${ }^{1}$ Winter dysentery outbreak versus no outbreak.

${ }^{2}$ Average milk production (L/cow per day) for 21 to 8 days before the day of notification.

${ }^{3}$ Number of days after notification of outbreak.

${ }^{4}$ Slopes $1-3$ were the coefficients generated from a cubic spline of the interaction of $\mathrm{WD}^{1} \times$ days ${ }^{3}$.

than for a WD- herd, given equal values before the outbreak. This was equivalent to an estimated average difference in free fatty acids between $\mathrm{WD}+$ and $\mathrm{WD}-$ herds of $11 \%$.

\section{DISCUSSION}

This study estimated the loss in milk production associated with a farmer-reported outbreak of WD to be 15\% (2 d after notification) at the herd level. For an average herd, the total estimated loss per cow was $51 \mathrm{~L}$ for the entire study period, from $7 \mathrm{~d}$ before $19 \mathrm{~d}$ after notification. Former studies vary widely with respect to the magnitude of drop in milk yield. A few studies have explored the effect of WD on milk production at the herd level. One study reported that $90 \%$ of farmers

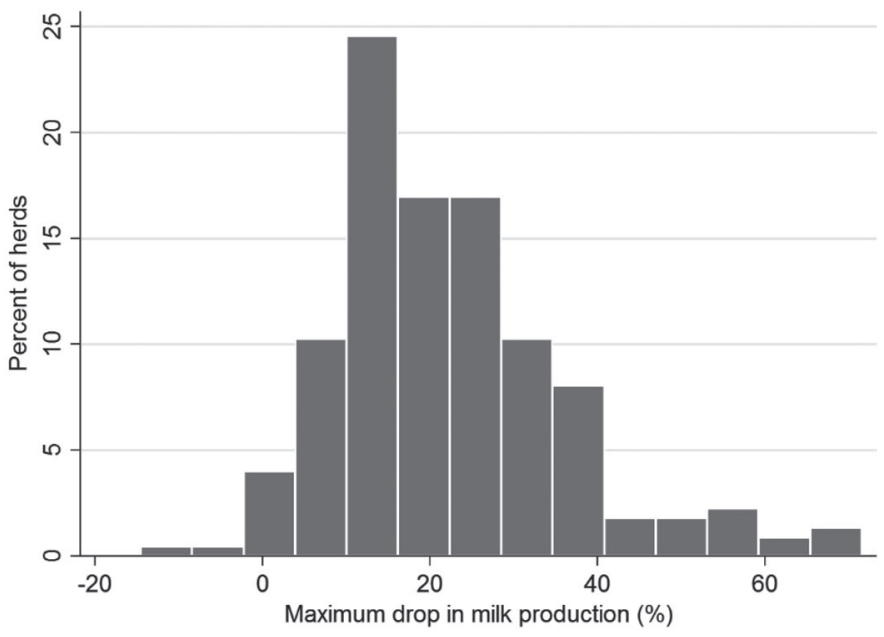

Figure 4. Histogram showing the distribution of maximum drop in milk production for herds that reported outbreak of winter dysentery (WD+). Maximum drop was calculated as the difference between the minimum daily production from 0 to $19 \mathrm{~d}$ after the day of notification and the average production before the outbreak (from 21 to $8 \mathrm{~d}$ before the day of notification). had observed a decrease in milk yield after WD, but farmers were not asked to quantify the loss (Tråvén et al., 1993). A study describing an outbreak of WD in 2 herds in Canada reported that herd-level milk production dropped to less than half of normal production (Durham et al., 1989), and Jactel et al. (1990) estimated a drop of 6 to $30 \%$, based on outbreaks in 7 herds. The latter study emphasized the large variation in severity of disease among the study herds, which was in line with the large spread in drop in milk production we found in the present study (Figure 4). Studies including only a few herds generally have limited generalizability, and that, combined with large variations in severity at both the cow and herd level, likely contributes to variations in estimates of the effect of WD on milk production between studies. An observational study

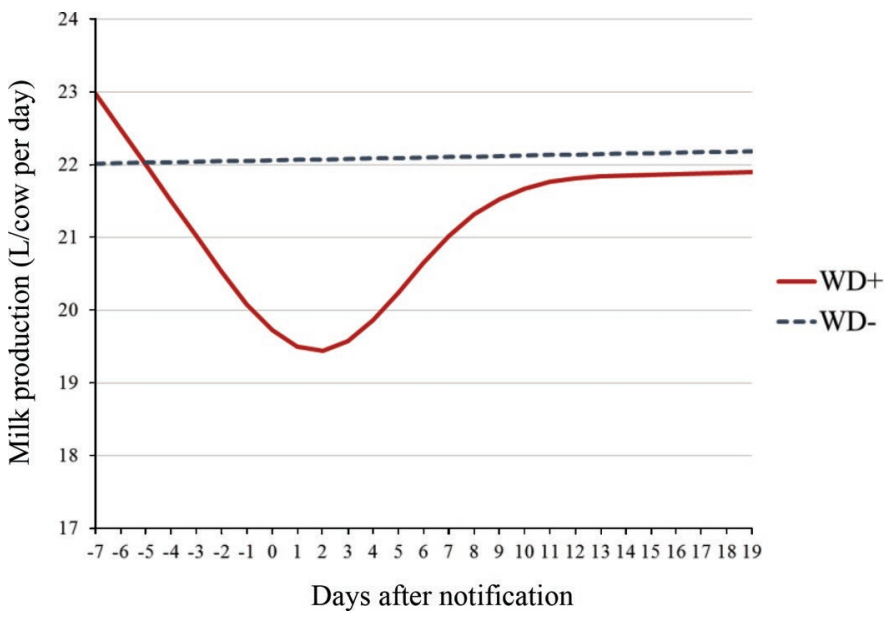

Figure 5. Predicted values of herd-level milk production (measured in $\mathrm{L} /$ cow per day) for herds that reported outbreak of winter dysentery $(\mathrm{WD}+)$ and herds that did not report winter dysentery (WD-) estimated from a linear mixed model, adjusting for milk production before the outbreak. Milk production before the outbreak was set to the study sample mean of $22.2 \mathrm{~L} /$ cow per day for 21 to $8 \mathrm{~d}$ before the day of notification. Color version available online. 
by Beaudeau et al. (2010) did not reveal any effect of seroconversion for bovine coronavirus in pooled milk samples of primiparous cows on test-day milk yield. However, seroconversion for bovine coronavirus does not necessarily mean that the herd had a WD outbreak. Furthermore, samples were taken 6 mo apart, making the exact time of virus introduction unclear, and the use of test day records for milk yield provides an additional limitation, because they are typically taken 1 month apart. Tråvén et al. (2001) found that milk production was reduced by 19 to $56 \%$ at the cow level in an experiment with 5 naturally infected cows. Comparing herd-level evaluations to cow-level studies is problematic, because a herd might consist of a mixture of naïve, immune, noninfected and infected animals, and the infection might vary from subclinical to severe. For the same reason, the results of the present study are not generalizable to individual cows. The relatively large sample size, the cohort of WD- herds from the same area for comparison, and access to milk shipment data for calculations of daily milk production were major strengths of the present study.

Milk production in the WD+ herds was still reduced $150 \mathrm{~d}$ after outbreak, compared with a slight increase in production for the WD- herds. However, uncertainty about causal inference increases with time since an outbreak. Furthermore, the long-term effect likely depends on the number of cows infected, the duration of clinical signs in the herd, and the number of new cows calving in the period after outbreak. Hence, the factors affecting long-term effects at the herd level are likely complex. We had no information on the factors mentioned in the current study. Virtually no other studies exist describing the long-term effects of WD, although Jactel et al. (1990) described reduced production up to $28 \mathrm{~d}$ for 1 study cow, and Clark (1993) stated that decreased production might last several months.

This is the first large-scale study to show altered milk composition as an effect of WD. The change in composition was small except for the increase in free fatty acids of about $11 \%$ for WD+ herds. Jactel et al. (1990) reported a decline in fat and protein content in 2 herds with WD outbreaks, but did not measure free fatty acids. However, an increase in free fatty acids has been described for bovine herpes virus 1 (Rola et al., 2015), and might be associated with negative energy balance due to anorexia or increased energy demand in diseased cows. The fat/protein ratio has been used as an indicator of lipo-mobilization (Toni et al., 2011), and the observed increase in this parameter gives additional support to the theory that negative energy balance is a consequence of WD. Increased free fatty acids in milk can be associated with reduced quality and cause offflavor (Santos et al., 2003), and are therefore important for farmers for economic reasons, because they might affect the price of the milk.

In the present study, we found that the maximum difference in milk production between the $\mathrm{WD}+$ and WD - groups was at d 2 after the notification date. However, we did not know the exact date of peak outbreak in terms of severity of clinical signs or maximum morbidity, because the farmer might have made the report before or after this peak. Figure 4 shows that a few herds did not experience a drop in milk production within the study period. It seems likely that we failed to capture the maximum effect of WD within the investigated time period for some WD+ herds, contributing to underestimation of milk loss.

The diagnosis in this study was based on clinical signs without laboratory confirmation for the majority of herds. However, the rapid spread of disease strongly indicated a contagious disease, and bovine coronavirus was confirmed as causative agent in some herds where diagnostics was performed. The Norwegian dairy herd is free of many infectious diseases that could be mistaken for WD. Feed-related diarrhea is also a differential diagnosis for WD, and because farmers' ability to distinguish WD from other causes of diarrhea probably differs, some exposure was likely misclassified in the WD+ group. Reporting of WD to the advisory service of the dairy company was done voluntarily, and because this might be associated with underreporting, misclassification of exposure was also likely present in the WD- group. Assigning pseudo-notification dates was done to minimize this problem: although many herds recorded as WD - probably had an outbreak during the winter season of 2011 to 2012 but failed to report it, it was less likely that such an outbreak would fall within the $27 \mathrm{~d}$ that represented the time at risk for this analysis. Altogether, the uncertainty regarding time of outbreak, the likely underreporting of WD, and the fact that the diagnosis was done by farmers means that the drop in milk production found in this study should be considered a conservative estimate (bias toward the null). As well, the negative effect of WD on milk production likely represents only a part of the total economic loss associated with a WD outbreak. Other effects of WD, such as adverse effects on reproduction, effects on calves and young stock, and treatment costs were not investigated in this study.

The initial differences between WD+ and WD- herds with respect to milk production (before the outbreak) were considerable (see Table 1). Hence, it was necessary to adjust for the difference in milk production before exposure to draw inferences from comparisons of the 2 groups. We did this analytically by including prior milk production in the model. The WD+ herds were also larger than the WD- herds on average (see 
Table 1), indicating that large herds were more likely to make a report, or that large herds had increased risk of clinical outbreak of WD. The latter has been described by White et al. (1989). The milk production values in Table 1 were averaged over the number of days in the table range, and are not comparable to the maximum drop estimated by the model.

The internal validity of this study was deemed acceptable after bias was minimized as described above. However, the milk composition analysis data were available for a smaller subset of the study herds, so selection bias cannot be ruled out for this part of the analysis. The external validity was considered good for the Norwegian population of dairy herds, because $98 \%$ of all dairy herds were members of the Norwegian Dairy Herd Recording System in 2013 (Espetvedt et al., 2013), and the herds in the study area were not likely to differ significantly from Norwegian dairy herds across the country with respect to management systems and breeds. The results are likely also valid for other populations of smaller-scale dairy herds in temperate areas.

Our results indicate that the effect of WD on milk production at the herd level is considerable. We also found an increase in free fatty acids and fat/protein ratio, indicating that WD can induce negative energy balance and adversely affect milk quality. The findings of this study emphasize the importance of preventive measures and should encourage farmers, veterinarians, and others to avoid between-herd spread of bovine coronavirus.

\section{ACKNOWLEDGMENTS}

The authors gratefully acknowledge TINE SA for access to milk shipment data and the Norwegian Dairy Herd Recording System. We sincerely thank Guro Sveberg for compiling the farmer reports. This project was funded by the Research Council of Norway (NFR-project No 224771/E40), the Norwegian Research Funding for Agriculture and Food Industry, and TINE SA. The Norwegian University of Life Sciences is acknowledged for providing financial support for the $\mathrm{PhD}$ student (Toftaker).

\section{REFERENCES}

Åkerstedt, J., M. Jonsson, S. Klevar, and T. Mørk. 2016a. The surveillance programme for bovine virus diarrhoea (BVD) in Norway 2015. In Surveillance Programmes for Terrestrial and Aquatic Animals in Norway. Annual Report 2015. Norwegian Veterinary Institute, Oslo, Norway.

Åkerstedt, J., M. Jonsson, and T. Mørk. 2016b. The surveillance programme for infectious bovine rhinotracheitis (IBR) and infectious pustular vulvovaginitis (IPV) in Norway 2015. In Surveillance Programmes for Terrestrial and Aquatic Animals in Norway. Annual Report 2015. Norwegian Veterinary Institute, Oslo, Norway.
Alenius, S., R. Niskanen, N. Juntti, and B. Larsson. 1991. Bovine coronavirus as the causative agent of winter dysentery: Serological evidence. Acta Vet. Scand. 32:163-170.

Beaudeau, F., A. Ohlson, and U. Emanuelson. 2010. Associations between bovine coronavirus and bovine respiratory syncytial virus infections and animal performance in Swedish dairy herds. J. Dairy Sci. 93:1523-1533. https://doi.org/10.3168/jds.2009-2511.

Boileau, M. J., and S. Kapil. 2010. Bovine coronavirus associated syndromes. (Special Issue: Emerging, reemerging, and persistent infectious diseases of cattle.). Vet. Clin. North Am. Food Anim. Pract. 26:123-146.

Clark, M. A. 1993. Bovine coronavirus. Br. Vet. J. 149:51-70. https:// doi.org/10.1016/S0007-1935(05)80210-6.

Dohoo, I. R., W. Martin, and H. Stryhn. 2009. Cohort studies. Pages 167-180 in Veterinary Epidemiologic Research. 2nd ed. AVC Inc., Charlottetown, Prince Edward Island, Canada.

Durham, P. J. K., L. E. Hassard, K. R. Armstrong, and J. M. Naylor. 1989. Coronavirus-associated diarrhea (winter dysentery) in adult cattle. Can. Vet. J. 30:825-827.

Espetvedt, M. N., O. Reksen, S. Rintakoski, and O. Østerås. 2013. Data quality in the Norwegian dairy herd recording system: Agreement between the national database and disease recording on farm. J. Dairy Sci. 96:2271-2282. https://doi.org/10.3168/jds.2012-6143.

Fleetwood, A. J., S. Edwards, P. W. Foxell, and C. J. Thorns. 1989. Winter dysentery in adult dairy cattle. Vet. Rec. 125:553-554.

Gulliksen, S. M., E. Jor, K. I. Lie, I. S. Hamnes, T. Løken, J. Åkerstedt, and O. Østerås. 2009. Enteropathogens and risk factors for diarrhea in Norwegian dairy calves. J. Dairy Sci. 92:5057-5066. https://doi.org/10.3168/jds.2009-2080.

Heier, B. T., A. Tarpai, B. Bergsjø, S. Kalberg, and M. Hofshagen. 2016. The surveillance programme for Salmonella in live animals, eggs and meat in Norway 2015. In Surveillance Programmes for Terrestrial and Aquatic Animals in Norway. Annual Report 2015. Norwegian Veterinary Institute, Oslo, Norway.

Jactel, B., J. Espinasse, M. Viso, and H. Valiergue. 1990. An epidemiological study of winter dysentery in fifteen herds in France. Vet. Res. Commun. 14:367-379.

Kleinbaum, D. G., L. L. Kupper, and H. Morgenstern. 1982. Epidemiologic research. Principles and Quantitative Methods. John Wiley \& Sons, Inc., Belmont, CA.

Klem, T. B., E. Rimstad, and M. Stokstad. 2014. Occurrence and phylogenetic analysis of bovine respiratory syncytial virus in outbreaks of respiratory disease in Norway. BMC Vet. Res. 10:15 https://doi.org/10.1186/1746-6148-10-15.

Lyons, N. A., N. Alexander, K. D. C. Stärk, T. D. Dulu, K. J. Sumption, A. D. James, J. Rushton, and P. E. M. Fine. 2015. Impact of foot-and-mouth disease on milk production on a large-scale dairy farm in Kenya. Prev. Vet. Med. 120:177-186. https://doi. org/10.1016/j.prevetmed.2015.04.004.

Paton, D. J., K. H. Christiansen, S. Alenius, M. P. Cranwell, G. C. Pritchard, and T. W. Drew. 1998. Prevalence of antibodies to bovine virus diarrhoea virus and other viruses in bulk tank milk in England and Wales. Vet. Rec. 142:385-391. https://doi. org/10.1136/vr.142.15.385.

Rola, J. G., M. Larska, M. Grzeszuk, and J. Rola. 2015. Association between antibody status to bovine herpesvirus 1 and quality of milk in dairy herds in Poland. J. Dairy Sci. 98:781-789. https:// doi.org/10.3168/jds.2014-8781.

Saif, L. J. 1990. A review of evidence implicating bovine coronavirus in the etiology of winter dysentery in cows: An enigma resolved? Cornell Vet. 80:303-311.

Santos, M. V., Y. Ma, Z. Caplan, and D. M. Barbano. 2003. Sensory threshold of off-flavors caused by proteolysis and lipolysis in milk. J. Dairy Sci. 86:1601-1607. https://doi.org/10.3168/jds.S00220302(03)73745-X.

Statham, J. M., L. V. Randall, and S. C. Archer. 2015. Reduction in daily milk yield associated with subclinical bovine herpesvirus 1 infection. Vet. Rec. 177:339 https://doi.org/10.1136/vr.103105.

Sviland, S., T. B. Johansen, S. Klevar, M. Valheim, and M. E. Jonsson. 2015. The surveillance programme for Brucella abortus in cattle in Norway 2014. In Surveillance Programmes for Terrestrial 
and Aquatic Animals in Norway. Annual Report 2014. Norwegian Veterinary Institute, Oslo, Norway.

Toftaker, I., J. Sanchez, M. Stokstad, and A. Nødtvedt. 2016. Bovine respiratory syncytial virus and bovine coronavirus antibodies in bulk tank milk - risk factors and spatial analysis. Prev. Vet. Med. 133:73-83. https://doi.org/10.1016/j.prevetmed.2016.09.003.

Toni, F., L. Vincenti, L. Grigoletto, A. Ricci, and Y. H. Schukken. 2011. Early lactation ratio of fat and protein percentage in milk is associated with health, milk production, and survival. J. Dairy Sci. 94:1772-1783. https://doi.org/10.3168/jds.2010-3389.

Tråvén, M., K. Näslund, N. Linde, B. Linde, A. Silván, C. Fossum, K. O. Hedlund, and B. Larsson. 2001. Experimental reproduction of winter dysentery in lactating cows using BCV: Comparison with BCV infection in milk-fed calves. Vet. Microbiol. 81:127-151. https://doi.org/10.1016/S0378-1135(01)00337-6.
Tråvén, M., J. Sundberg, B. Larsson, and R. Niskanen. 1993. Winter dysentery diagnosed by farmers in dairy herds in central Sweden: Incidence, clinical signs and protective immunity. Vet. Rec. 133:315-318.

Vittinghoff, E., D. V. Glidden, S. C. Shiboski, and C. E. McCulloch. 2012. Regression Methods in Niostatistics. 2nd ed. Statistics for Biology and Health. Springer, New York, NY.

White, M. E., Y. H. Schukken, and B. Tanksley. 1989. Space-time clustering of, and risk factors for, farmer-diagnosed winter dysentery in dairy cattle. Can. Vet. J. 30:948-951.

Yang, Y., W. Fan, Y. Mao, Z. Yang, G. Lu, R. Zhang, H. Zhang, C. Szeto, and C. Wang. 2016. Bovine leukemia virus infection in cattle of China: Association with reduced milk production and increased somatic cell score. J. Dairy Sci. 99:3688-3697. https:// doi.org/10.3168/jds.2015-10580. 